\title{
Integration of Oil Geology Internet Information Resources and Infrastructure for Science and Technology
}

\author{
Wei $\mathrm{HAO}^{*}$ \\ Department of Information Technology, \\ Institute of Disaster Prevention, \\ Sanhe Hebei, 065201,China \\ Email:conniehao@126.com
}

\begin{abstract}
The method was proposed to integrate network resources of Oil geology by difference modes based on the characteristic of china Oil geology network resources and integration pattern of network resources. The following primary network resources integration system was developed based the Web technology and database, VR, metadata technology: "Information System Oil Quality Database of Chain" by database integration mode, "VR practice base for geology teaching through experience" by portal website integration mode. The first internet information resources organization mode was completed. And with the theory of facilities and information infrastructure for science and technology, the facilities and information infrastructure for Oil geology science and technology was put forward, and the platform was designed and developed. Then the other network information resources were organized in the second mode. To further improve the efficiency and retrieval network of information resources of Oil geology of the development level, "search engine of Oil geology" by search engine integration mode was built, and the network resources of Oil geology were completed the third organization. By three times information resources organized, china Oil geology network resources organization was initially completed, so which can service for research and teaching in Oil geology.
\end{abstract}

Keywords-Oil geology; infrastructure for science and technology;network resources; metadata; integration mode

\section{INTRODUCTION}

Oil geology is the main branch of Oil science. And the Oil geology information is the important part of science information. Network resources on Oil geology are increasing with the development of network technology. But, it is difficult to achieve the consistency between the decentralization of out-of-order network resources and the concentricity of its demander. For making the best of the network resources, the technology platform, which integrates all kinds of network resources on Oil geology, is essential.

Based on the decentralization of china Oil geology network resources, the Oil geology infrastructure of science and technology with the Web technology and database, VR, metadata technology, was developed for deep integration of network resources. The Oil geology infrastructure of science and technology achieved the primary integration of china Oil geology network resources and can service for research and teaching in Oil geology.

\section{RESEARCH OVERVIEW ON OIL GEOLOGY NETWORK RESOURCES}

\section{A. Data analyze characteristics}

Oil geology network resources of China were collated. So, Types of information as follows:

- Network science and technology news. In Network news, timeliness should be the important characteristics.

- Policies and regulations and technical standards. This information has outstanding professional and most new.

- Scientific data. These data has a large percentage, and has a strong professional, so which is a foundation of scientific research.

- Academic resources. These data contains a mass of data and numerous and jumbled content, but has wide transmission range and speed.

- Communication information on the network. These data is "grey literature", which are promptness, time, globalization, freedom and dynamic.

- Others. This information is random, but modest professional.

Oil geology network resources of China were Collated and introduced from the source and content of these resources. Based on these results, the data types of oil geology network resources were summarized from general characteristics, which were laid the foundation for confirming the integration pattern of oil geology network resources. The data in oil geology network resources can be categorized into spatial data and attribute data.

1) Spatial data types include vector data, raster data and remote sensing data.

- $\quad$ vector data: Digitization, geophysical prospecting and geochemical exploration can be capable of achieving the vector data,eg reserves prediction figure, comprehensive geological histogram, profiles.

- raster data: Scanning thematic map can be capable of achieving the raster data, eg geological map, hydrogeological map.

- remote sensing data:TM,SPOT and aerial photo can be capable of achieving the remote sensing data,eg monitoring map.

2) Attribute data types include text and number data. 
- Text data:The attribute data of spatial data,reports and documents are text data,eg geological survey reports, resource prediction and assessment reports.

- Number data:Ttabular data, eg the data of environment geological, engineering geological ect.

B. The integration pattern of oil geology network resources

According the data were poor shared, the search results cannot meet the specific needs of users, general search engine cannot be combined with specialty, the new method was proposed to by difference modes based on integration pattern of network resources [1-3]. For example, the database integration mode was introduced for database resources, portal website integration mode and VR for threedimensional space resources, search engine mode for website information. The integration patterns make it feasible to take full advantage of network resources of Oil geology.

- About scientific data, a data base is used to store transmit information.

- Geological information can be integrated by portal website with VR.

- Conventional network information can be integrated by portal website with HTML.

- Whole network information can be integrated by search engine for retrieval.

\section{FACILITIES AND INFORMATION INFRASTRUCTURE FOR OIL GEOLOGY SCIENCE AND TECHNOLOGY}

Research Status about domestic and foreign facilities and information infrastructure has been investigated and this concept was applied in the Oil geology, so the conception of the facilities and information infrastructure for Oil geology science and technology was defined. The overall design and realization of the project for facilities and information infrastructure for Oil geology science and technology were proposed based on the Web technology and database, VR, metadata technology. This overall design kept to the second network information resources organization, which realized the traditional single resource database management system to one higher level-the multi-resource database brand-new information management pattern.

Facilities and Information Infrastructure for Science and Technology is an important component of State Innovation System. It is serving for the society in Science and Technology Progress and Innovation of Shoring of Foundation. It includes three fields: one is safeguards system of substance and information, another is core of sharing systems, and the other is the professional person.

Facilities and Information Infrastructure for Oil Geology Science and Technology is material conditions and information integration in scientific and technological research work ,which is hardware (experimental materials, apparatus, equipment, facilities, etc.) and software (computer software, data base, science and Technology Literature), and the technical support, services and research space [4-5]. So that the user can conveniently access the needed information, in order to promote the effective use of petroleum resources
Facilities and Information Infrastructure for Oil Geology Science and Technology includes three fields: one is base and research data, another is teaching and popular science data, the other is the experimental simulation data. The logical structure of FIIOG as shown is in figure1.

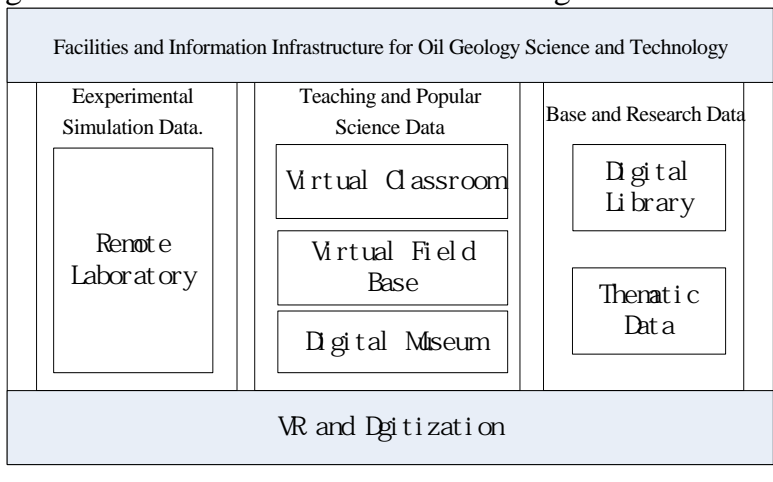

Figure 1. Logical structure of FIIOG

\section{A. Constituting oil geology metadata standard}

New useful metadata will be discovered from information resources by data mining technology, and formulate Oil geology metadata standard. On the basis of the Earth System Science Metadata Standard (Secondary Structure), new standard will refine metadata in Oil geology science[6-7]. Meanwhile, a series of standards about its mark, contents, data pattern were proposed. The configuration figure of oil geology metadata as shown is in figure2.

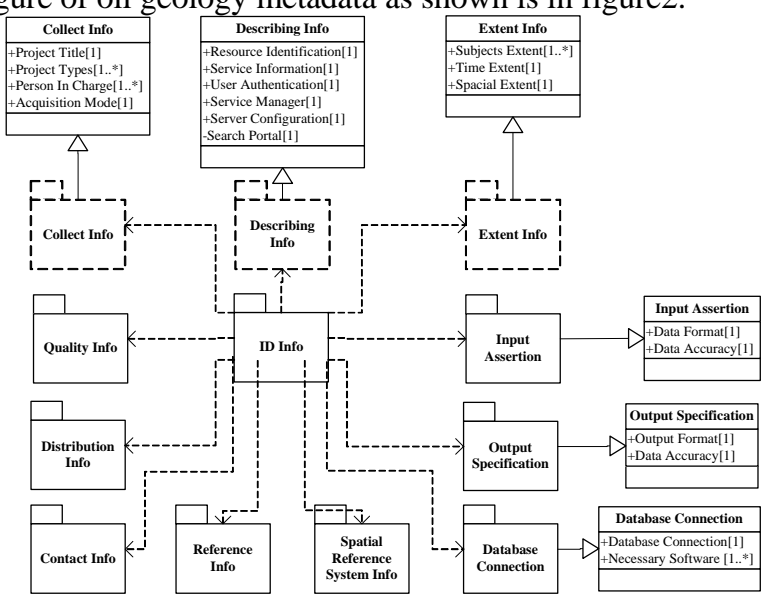

Figure 2. The configuration figure of coal oil metadata

\section{B. Network security research of open resource platform}

The security policy of open style platform under network environment was investigated comprehensively and studied. In view of Chinese Oil geology platform own unique feature, data characteristic as well as present question, it formulates this platform of security strategy. The security strategy was proposed including network layer, application layer and data transportation layer of the platform.

In the data transmission process, encryption and decryption problems which is between the client and server, 
usually with SSL public key technology to achieve. So it ensure that the important and sensitive data transmission security.

It has two important functions: (a) authentication of the server and client at the beginning of the session, and (b) encryption/decryption of data exchanged between the two parties during the session.

Private (or symmetric) key algorithms such as DES, RC4, IDEA, etc. are typically used for bulk data encryption. By design, these algorithms are highly sequential in nature and use many rounds of computations.

According to own characteristics of data types in Database, the DES encryption algorithm have been chosen as the database data encryption algorithm in .NET system. CreateEncryptor (Key,IV) was used in the encryption process. And CreateDecryptor(Key,IV) was used in the decryption process. The code of data encryption as shown is in List 1.

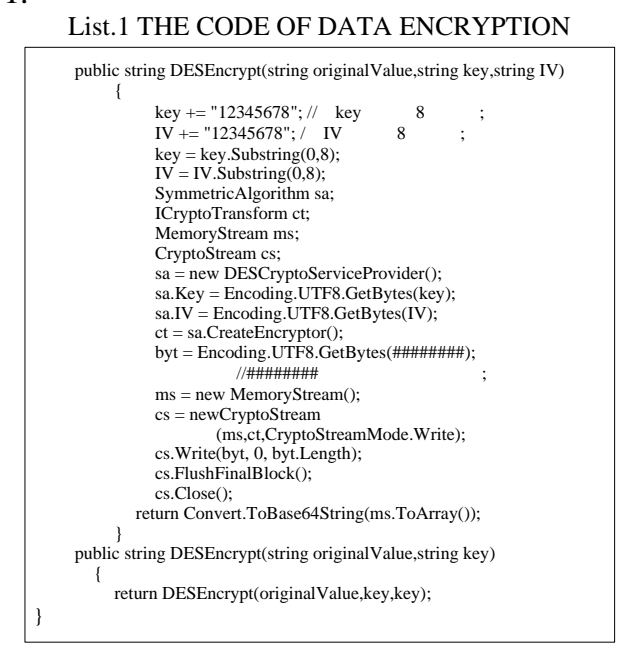

\section{APPLICATION RESEARCH}

\section{A. Experience type geology teaching \& practicing platform}

The characteristic of existing experience type teaching was analyzed. And then it proposes experience type geology teaching virtual platform based on network by virtual reality, three dimensional visualization technologies, which achieved the 3D information of the first integrated network resources. Using minute stratified pattern, it proposes the platform's architecture, realizes virtual rural trail. Its functions such as virtual teaching and social application provide modernized practice for teaching, research and popular science education [8-11].

\section{1) Overview of virtools}

Virtools is an extensive collection of technologies for 3D visualization. The Virtools technologies are broadly grouped as:

- An Authoring application.

- A Behavioral Engine (CK2).

- A Rendering Engine.

- A Web Player.
- A Software Development Kit (SDK).

2) Application

Development flow of virtual geoscience's cognition practice system as shown is in figure3.

Modeling

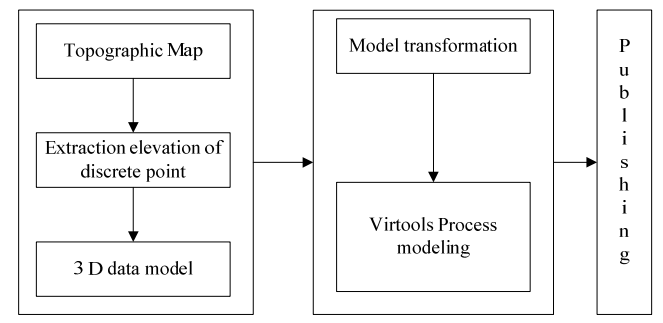

Figure 3. Development flow of virtual geoscience’s cognition practice system

A three-dimensional model was preserved to the NMO file. That was imported to the Virtools Dev. Then Virtools Server was set in the Virtools Server Controller. 3D model was establishment, which is as shown in figure4.

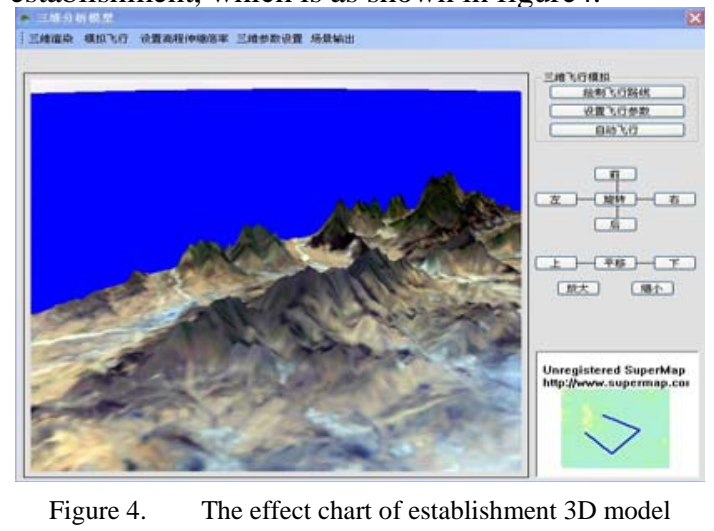

\section{B. Oil geology profession search engine}

On the analysis of general search engine, this paper establishes the intelligent professional search engine in oil geology by using vertical search engine, metadata search engine and improved sorting algorithm. Meanwhile, it also establishes the specialized search synonymy database to retrieval key words. It is advantageous in breaking the only retrieval to specialized database, expanding the scope of specialized information and enhancing the accuracy of retrieval results. Oil geology profession search engine was established, which achieved the oil geology of the third integrated network resources, improve the network information retrieval efficiency of resources utilization and development.

1) Overview of search engine

Comparing with the traditional full-text search engine, the vertical search engine can provide more professional and effectively information. The users can avoid filtering usable and professional information from mass data when they use the vertical search engine. This is research focus of search engine. At present, the vertical search engine adopted the system structure which is similar with the full-text search 
engine [12-13]. It had high level in the professional association degree. Conforming to the universal full-text search engine, it is also confronted with the problem of low-recall ratio and high dissipation of web resource. This article provides the system structure of the vertical search engine which based on recta-search to solve these problems, the level of the professional association degree is declined, but the recall ratio is improved.

\section{2) Application}

Because of Meta-search engine had higher recall ratio, we design a vertical search engine which adopts the method of the information collection which is based on the Metasearch engine. The system adds the function of information collection and analysis to adapt to the demand of the vertical search engine.

Information search is the core of the search engine. This article imports data mining to analysis the collected information and it reduces correlative rules between words and key words from the well-pleased information. We provide the concept of the adelomorphic key words which used in the information search. Experiment proves that the search which added the adelomorphic key words Call improve the professional association degree of the results. The architecture of oil geology search engine as shown is in figure5.

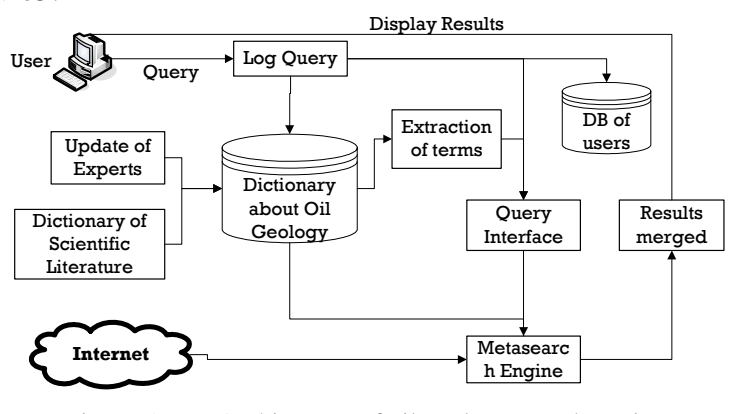

Figure 5. Architecture of oil geology search engine

The result of running on meta-search engine is as shown in the figure6.

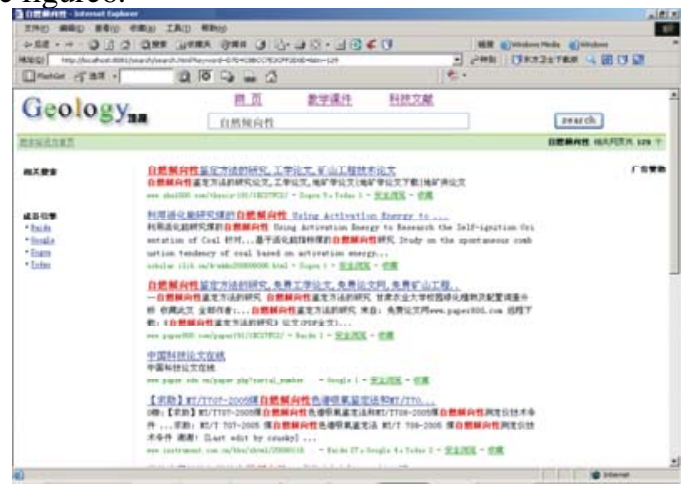

Figure 6. The result of running on meta-search engine

\section{CONCLUSION}

According to analysis and research about the network resources integration mode, interrelated network technology, the new method was proposed to by difference modes based on integration pattern of network resources to achieve the integration of Oil geology network resources. Information system of Oil quality database of China, virtual geoscience's cognition practice system, Oil geology profession search engine and facilities and information infrastructure for Oil geology science and technology can explain the first, the second and the third integration mode of network resources. But because lacks of time and experience, some work also only is in the preliminary stage and needs the future to make the further attempt.

\section{ACKNOWLEDGMENT}

Authors (HAO Wei) thank the financial support from Special Fund of Fundamental Scientific Research Business Expense for Higher School of Central Government (Projects for young teachers) (ZY20120211).

\section{REFERENCES}

[1] R.X.Li, "Shift of functions of sci-tech periodicals in web environment of open, collection and common sharing of scholarly resources,". Acta Editologica, vol.24, Oct.2012,pp.414-418.

[2] Y.H Zhang, "Integration of the network academic resources and its application,”.Library Theory and Practice,vol.38,Nov.2011,pp.34-36.

[3] P.Gu, "Policy Supports for Network Academic Resource Construction in China,”.Pioneering with Science \& Technology Monthly, Apr.2010,pp.122-124.

[4] R.D.Liu, W.B Chu, Y.Q Zhu, "Study on Key Problems of NSTI of China in Operation \& Service Stage,”. Journal of Modern Information, vol.32, Nov.2012,pp.51-54.

[5] D.J.Zhong, W.WANG, "The Effects of and Countermeasures for the Construction of the Fundamental Conditions Platform of Science and Technology in Shanxi Province,”. Sci-Tech Information Development \& Economy, vol.22, Oct .2012,pp.142-145.

[6] N.M.YAO,Y.SHAN,Y.K.TIAN, "Research of Metadata Management Strategy on Object-based Storage System,”. Journal of Chinese Computer Systems, vol.33, Sep.2012,pp.1908-1912.

[7] W.T Hu, T.H.Chi, L. Peng, "Design and implementation of Remote Sensing Data Auto-Loading System based on metadata,”. Science of Surveying and Mapping, vol.37, Sep.2012,pp.222-223+234.

[8] Q.W. Cui, W.L Sun, X.J. Wan, "Study on the Visual Simulation System of the Oil Field Based on Virtual Reality Technology," Machinery Design \& Manufacture, Sept.2012,pp. 249-251.

[9] H.Zou, J.S Bao, J.L, “Application of Virtual Reality Technology in Oilfield Prodnction Construction,” Oil-Gasfield Surface Engineering, vol.31,Sept.2012,pp. 81-82

[10] Z.G.Fu, T.W.Wang, X.P. Ni, “ The Virtual Reality Technology and Its Application in Special Equipment Education Based on Virtools," Computer Engineering \& Sciencev,” vol.34,Jun.2012,pp. 97-100.

[11] J.S.Sun, "Design and Implementation of Virtual Reality Experimental System Based on the Knowledge in Subject Fields,” E-education Research,vol.33,Aug.2012,pp. 70-74.

[12] Y.Xue, "Research and Design on Scheduling Strategy of Metasearch Engine Based on Personalized Demand of Users," Coal Technology, vol.30,April.2011,pp. 219-221.

[13] X.Wang, X.X Liu,“ Research on Vertical Meta-search Engine Based on Association Rule Mining”, Computer Engineering, vol.37,Feb.2011,pp. 76-77+80 